\title{
Long-term relationships
}

\author{
Ecological research projects that span decades provide unprecedented insight into the functioning and dynamics \\ of populations, communities and ecosystems. We should treasure and protect them.
}

E cological processes rarely respect the time frames imposed by short-term projects and grants. In a period of unparalleled human-induced global change, the rapid alterations we currently see to natural communities and ecosystems may not be indicative of change in the mediumto-long term. Without high-quality baseline data from the recent past, predicting future responses is like betting on a horse race without first examining the form guide.

This is why the long-term datasets that we already have are so valuable, and why they should continue. In this issue, Gooseff et al. analyse 25 years of data from the McMurdo Dry Valleys LongTerm Ecological Research (LTER) project in Antarctica, and show that an influx of glacial meltwater during a single unusually warm summer was enough to elicit largescale changes to the biological communities of this fragile, extreme ecosystem. In an accompanying News and Views article, Dana Bergstrom praises the investment by the US National Science Foundation (NSF) in this project, and the 26 other LTER sites in the United States.

Identifying this kind of decadal stepchange requires data collected over timescales that capture the full range of ecosystem variability. In another study published this month, Pappas et al. highlight this issue of scale by showing that, over five orders of temporal magnitude spanning hours to decades, the variability in ecosystem functioning of non-tropical forests shrinks with increasing temporal scale. This decrease is constrained by meteorological variables acting on the system, but in such a way that their coupling is not adequately captured by current modelling approaches.

Analysis across these temporal scales was made possible by using data from FLUXNET (http://fluxnet.fluxdata.org/), a distributed network of more than 600 sensors capturing atmospheric variables across the globe, on all continents. Initiatives like this and the Nutrient Network (http:// www.nutnet.org/), supported by funding from the NSF Research Coordination Network programme, provide crucial globalscale tests of ecological theories, allowing us to reach more general conclusions than could be determined from experiments on smaller scales. This is not to downplay the importance of small-scale studies, but, as acknowledged by the NSF, these networks add value far beyond the sharing of data, by bringing together researchers from across international boundaries, fostering new collaborations, and sharing expertise.

These research networks will continue to build our knowledge about how ecosystems are responding to global change - if they are well supported. Unfortunately, funding by the NSF for ecological studies longer than four years in duration has been declining over the past 10 years, despite evidence that they may have a greater influence on policy than short-term experiments ${ }^{1}$.

Clear geographical gaps also exist in the distribution of long-term monitoring sites, especially among developing nations (for example, see Fig. 2 of ref. ${ }^{2}$ ). Although effort is being made to expand the breadth and capacity of these projects, such as through the International LTER network (ILTER; https://www.ilternet.edu/), there will always be uncertainty surrounding how such large-scale projects can be maintained. Payment by members can keep networks self-sustaining after start-up costs from central funding agencies elapse, as in the case of the ILTER ${ }^{3}$, but this relies on members sustaining their funding. Where research networks span diverse socioeconomic and political boundaries, it is vital that capacity building in developing nations is supported, for example through match-funding schemes to incentivize collaboration across nations (target 17.9 of the Sustainable Development Goals; https:// sustainabledevelopment.un.org/sdg17).

It is perhaps easy to see why long-term research might not be an attractive prospect for funders. In addition to high initial costs, guaranteeing sufficient funds may be problematic where the duration of the funding cycle is smaller than the duration of the study. These funds can only be distributed among a narrow group of recipients, while research outputs may also be lower in the short-term compared to if funds were split between many smaller projects.

When viewed from a broader perspective, however, it becomes clear that long-term work is more than the sum of its parts. The world's longest running grassland experiment, Park Grass, has contributed hugely to our understanding of biodiversity, agriculture, soil science, community dynamics, local adaptation and genetic drift since its inception in the late nineteenth century at Rothamsted Research in the $\mathrm{UK}^{4}$. Other long-term grassland biodiversity experiments such as those at Cedar Creek ${ }^{5}$ and Jena ${ }^{6}$ similarly explore the many facets of the biodiversity-ecosystem functioning relationship, while ongoing projects such as the forest plots at Barro Colorado Island in Panama have transformed our understanding of processes governing species diversity and abundance ${ }^{7}$. More recently, monitoring stations across the Qinghai-Tibet Plateau in China are revealing how high-altitude communities are responding to global change ${ }^{8}$.

Of course, it is not just in ecology where long-term experiments may reap scientific rewards. Richard Lenski's ongoing experiments with $E$. coli have reached more than 66,000 generations of selection, providing unique insight into evolutionary dynamics, while last month Rosemary and Peter Grant rightly received the Royal Society's Royal Medal for more than 40 years of work challenging ideas about the rapidity of evolutionary change among Darwin's finches in the Galápagos.

Along the way, these long-term projects will have played a part in the education, training and development of countless researchers involved in the collection and analysis of data. Organizations such as the Ecological Continuity Trust in the UK (http://www.ecologicalcontinuitytrust. $\mathrm{org} /$ ) are to be applauded for their efforts in supporting long-term research projects that also include grants specifically for undergraduate or postgraduate research projects, as well as small grants to support visiting scientists, students or public engagement. In a climate of international funding uncertainty, these broader educational and societal benefits should be moved to the forefront of the decisionmaking process.

Published: 22 August 2017

DOI: 10.1038/s41559-017-0306-4 


\section{References}

1. Hughes, B. B. et al. BioScience 67, 271-281 (2017).

2. Borer, E. T., Grace, J. B., Harpole, W. S.,

MacDougall, A. S. \& Seabloom, E. W. Nat. Ecol. Evol. 1, 0118 (2017).
3. Vanderbilt, K. \& Gaiser, E. Ecosphere 8, $\mathrm{e} 01697$ (2017).

4. Silvertown, J. et al. J. Ecol. 94, 801-814 (2006).

5. Tilman, D., Isbell, F. \& Cowles, J. M. Annu. Rev. Ecol. Evol. System. 45, 471-493 (2014).
6. Weisser, W. W. et al. Basic Appl. Ecol. http://doi.org/cbgg (2017).

7. Hubbell, S. P. The Unified Neutral Theory of Biodiversity and Biogeography (Princeton Univ. Press, Princeton, 2001). 8. Shen, M. et al. Glob. Change Biol. 22, 3057-3066 (2016). 